\title{
Modification of Natural Leather Properties via Grafting Polymerization of Glycidyl Methacrylate Monomer
}

\author{
Nadia Hussein \\ National Research centre \\ Raedah A.S. Alatawi \\ University of Tabuk \\ Marzough A. Albalawi \\ University of Tabuk \\ Hanan M. A. Al-Sayed \\ Ain Shams University \\ Abeer Abdulaziz H. Bukhari \\ University of Tabuk \\ U Faridi \\ University of Tabuk \\ Nadia H. Elsayed ( $\nabla$ nhussein@ut.edu.sa ) \\ University College-Alwajh
}

Original Research Full Papers

Keywords: Gycidyl methacrylate, Grafting, Leather, Dibutyl amine

Posted Date: February 1st, 2021

DOl: https://doi.org/10.21203/rs.3.rs-164226/v1

License: (9) (i) This work is licensed under a Creative Commons Attribution 4.0 International License.

Read Full License 


\section{Abstract}

Chrome tanned leather was grafted by poly (glycidyl methacrylate) (L-g-PGMA) via emulsion polymerization technique and the grafting yield 26\%. Epoxy content of the grafted leather samples was $69.4 \mathrm{mmol} / 100 \mathrm{gm}$. The obtained L-g-PGMA samples were impregnated in different dibutyl amine solutions using amine/ epoxy molar ratio ranging from 0.5 up to 2.5. The obtained samples were assessed through varying nitrogen analysis, infrared spectroscopy, thermogravemetric analysis (TGA) analysis and scanning electron microscope. It was found that the nitrogen content of the treated leather samples increases by increasing the dibutyl amine concentration up to amine/ epoxy molar ratio of 2 after which it decreases. The water absorption, tensile strength and elongation (\%) as well as hardness of the modified leather samples were studied and compared with the unmodified one. The colour strength values of dyed leather samples with acid dye were found to increase by grafting or by increasing the amine/epoxy molar ratio up to a value of 1.0 after which it decreases. On the contrary, the colour strength value of dyed leather sample with reactive dye sharply decreases after grafting with poly (glycidyl methacrylate). Samples grafted with glycidyl methacrylate and treated with dibutylacrylate amine exhibit increased colour strength which is directly related to the nitrogen content of the sample.

\section{Introduction}

Grafting of vinyl monomers onto leather and hide powder has been reported [1-4]. Graft polymerization is initiated by different initiation systems including $\mathrm{Ce}^{(\mathrm{IV})}$ ions [5], potassium permanganate [6], potassium persulphate [7] as well as redox systems such as potassium persulphate - ascorbic acid [8] and persulphate/bisulphate $[9,10]$. Graft copolymerization of glycidyl merthacrylate onto gelatin using peroxydis/phate in aqueous medium was studied [11]. It was found that the grafting percent increases initially then decreases by increasing temperature, time, and initiator concentration and; the opposite holds true for monomer concentration. The grafted copolymers were characterized by IR and evaluated with respect to the percent swelling, percent dye uptake and mechanical properties [11].

Improvement of the properties of leather can be made by grafting it with different monomers using the emulsion polymerization technique $[12,13]$. Latex polymers can also be used as finishing agent to modify different leather properties such as lustering [14], water resistance [15] and quality [16,17]. The present work aims to study the characteristic behaviour and other properties of leather-g-PGMA along with tertiary aminated leather obtained by reacting the former with dibutyl amine. Characterization and properties of these substrates were undertaken using FTIR, thermogravimetric analysis, scanning electron microscope, measurement of mechanical properties (tensile strength, elongation and hardness), in addition to determination of water absorption and dyeing performance using acid and reactive dyes.

\section{Experimental}

\section{Materials}




\section{Leather}

Chrome-tanned cow leather supplied from Tabuk region - KSA was selected for this investigation. The leather was washed with water drained and neutralized.

\section{Dyestuff:}

Two different dyes were used in this work, namely an acid dye (Acidol Brown) supplied by BASF, and a reactive dye, (Cibacron Scarlet Red, 2G-E) supplied by Ciba-Geigy.

\section{Chemicals}

Glycidyl methacrylate, Dibutyl amine, potassium persulphate, toluene and butanol supplied by MerckSchuchardt, Germany. Ferrous ammonium sulfate and Sodium dodecyl sulfate were supplied by BDH Company. Other chemicals were of laboratory grade.

\section{Graft copolymerization of glycidyl methacrylate onto leather}

Leather-g-PGMA having graft yield of $26 \%$ and epoxy content $69.4 \mathrm{mmol} / 100 \mathrm{gm}$ was prepared according to the emulsion polymerization technique as follows: $0.35 \mathrm{~mol} / \mathrm{l}$ of Glycidyl methacrylate was added to a conical flask containing $2.87 \times 10^{-2} \mathrm{~mol} / \mathrm{l}$ of sodium dodecyl sulfate emulsifier solution. $5 \mathrm{ml}$ of each of Toluene and butanol as well as $5 \mathrm{gm}$ of leather were also added and the flask components were mechanically stirred at $200 \mathrm{rpm}$ for $30 \mathrm{~min} .0 .01 \mathrm{~mol} / \mathrm{l}$ Ferrous ammonium sulfate and $1 / 2 \times 10^{-2} \mathrm{~mol} / \mathrm{l}$ potassium persulphate/acetone sodium bisulphite adduct [18] as a developed redox initiation system were added to the flask and the graft polymerization is hold for $90 \mathrm{~min}$ at $50^{\circ} \mathrm{C}$ using a material to liquor ratio of $1 / 20$. The homopolymer is extracted from the grafted leather by soxetlet extraction using toluene till a constant weight of leather.

The grafting yield was calculated according to the following equation: -

Grafting yield $=w_{2}-w_{1} / w_{1} \times 100$

Where, $w_{2}=$ weight of grafted leather and $w_{1}=$ weight of ungrafted leather

\section{Treatment of grafted leather with dibutyl amine}

The leather-g-PGMA having graft yield of $26 \%$ and epoxy content $69.4 \mathrm{mmol} / 100 \mathrm{gm}$ was immersed in dibutyl amine (DBA) aqueous solutions at different concentrations. The treatment was carried out using amine/epoxy content molar ratios of $0.5,1.0,1.5,2.0$ and 2.5 for $3 \mathrm{hrs}$ at $80^{\circ} \mathrm{C}$. The treated leather samples were thoroughly washed with distilled water and oven dried at $80^{\circ} \mathrm{C}$.

\section{Dyeing methods:}


Each of ungrafted leather, leather-g-PGMA and leather-g-PGMA treated with DBA were independently dyed with two classes of dyestuff namely acid and reactive dyes. The dyeing was carried out as per the conventional exhaustion method at dye concentration of $0.2 \%$, liquor ratio of $1: 50, \mathrm{pH}$ of $4-4.5$ for acid dyeing and 6.8-7.2 for reactive dyeing at $80^{\circ} \mathrm{C}$ for $1 \mathrm{hr}$.

\section{Testing and analysis}

The nitrogen content was determined according to Kjeldahl method [19]. The infrared analysis (IR) was carried out using a Perkin- Elmer FTIR Spectrophotometer MODEL 1650, USA. Jeol scanning microscope (Japan) JSM- 400 was used for microscopy. The thermogravimetric analysis (TGA) were carried out at a temperature range starting from the room temperature to $600^{\circ} \mathrm{C}$ under inert nitrogen atmosphere with heating rate of $10^{\circ} \mathrm{C} / \mathrm{min}$ using Shimadzu TGA-50 and Shimadzu DSC -50 , Japan.

\section{Mechanical measurements}

Dumbells shape specimen $5 \times 1 \mathrm{~cm}$ and $4 \mathrm{~mm}$ neck width was used for the measurement of the ultimate tensile strength and elongation at break using an Instron Machine (model 1195). The hardness was measured by shore A, Harterpufer apparatus Din 53505 according to ASTM D 2240.

\section{Color measurements}

The color strength $(\mathrm{K} / \mathrm{S})$ values of all examined dyed samples were calculated using the Kubelka Munk equation [20] using SDL Optimatch Colour Matching System, England. MgO was used as standard white.

\section{Determination of water absorption:}

The test for determination of water absorption capacity was based on immersion of circle specimens into water for different interval time (15 min, $2 \mathrm{hrs}, 24 \mathrm{hrs})$ at room temperature, water absorption capacity $(\omega)$ was determined from the relationship).

$(\omega)=W-$ Wo $/$ Wo $X 100$

Where $\mathrm{W}=$ weight of grafted leather after immersion in water

Wo $=$ weight of grafted leather before immersion in water.

\section{Results And Discussion}

Chemical modification of leather is usually carried out to improve its properties with a view to satisfy enduser application. Desirable properties for leather are its hydrophobicity, stability, and mechanical properties as well as dyeability. In our study, glycidyl methacrylate was grafted onto leather with a graft yield of $26 \%$ (ca. $0.07 \mathrm{~mol} / 100 \mathrm{gm}$ epoxy content) using the emulsion polymerization technique. The grafted leather (GL) was treated with five different concentrations of dibutyl amines (DBA) using DBA/epoxy content molar ratios of $0.5,1.0,1.5,2.0$, and 2.5. Unmodified leather (BL), grafted leather (GL) 
as well as the five aforementioned GL treated with DBA $\left(\mathrm{GLAm}_{1}, \mathrm{GLAm}_{2}, \mathrm{GLAm}_{3}, \mathrm{GLAm}_{4}\right.$ and $\mathrm{GLAm}_{5}$, respectively), were characterized and evaluated as detailed under.

It is well known that introduction of tert-amino group to polymeric material such as starch, cellulose and/or polyester would certainly affect their hydrophilic character to some extent [21-23]. The magnitude of the hydrophilic-hydrophobic property of the modified polymer greatly depends on the number and type of alkyl group attached to the nitrogen atom of tert-amino group. Our target in this work is focused toward getting a delicate balance between improving the dyeing, thermal, morphological and mechanical properties on one side, and maintains the hydrophobic character of leather on the other side.

\section{Infrared spectra of leather}

The IR Spectra of BL, GL and GLAm are shown in Figure 1. It is evident (Figure 1b) that the presence of the band at $906 \mathrm{~cm}^{-1}$ is due to the epoxy group of the glycidyl methacrylate which is only observed for GL thereby proofing occurrence of graft copolymerization of GMA monomer onto leather. In case of GLAm (Figure 1c), the presence of a broad band at the range between $3412-3484 \mathrm{~cm}^{-1}$ is characteristic for the tert-amino group of the GLAm. The presence of this band manifests the chemical interaction between the epoxy group of the monomer and DBA. On the other hand, the presence of a band in the range 1637-1658 $\mathrm{cm}^{-1}$ as well as a band in the range $2964-2968 \mathrm{~cm}^{-1}$ for all studied leather samples (Figure $1 \mathrm{a}-\mathrm{c}$ ), could be related to the carbonyl group as well as $\mathrm{C}-\mathrm{H}$ stretching, respectively, of the main leather structure.

\section{Thermogravemetric analysis}

Thermogravemetric analysis TGA is a simple and accurate method for studying the decomposition pattern and the thermal stability of the polymers. Figure (2) shows the primary thermograms and derivatograms for $\mathrm{BL}, \mathrm{GL}$ and $\mathrm{GLAm}_{4}$. As it evident, for $\mathrm{BL}$, there is an initial weight loss of $12.6 \%$ around $100^{\circ} \mathrm{C}$, which is mainly due to the evaporation of absorbed moisture [24]. Also, the main decomposition for the unmodified leather sample proceeds in one step starts at $309^{\circ} \mathrm{C}$ and end at $362^{\circ} \mathrm{C}$ with the decomposition temperature $\left(\mathrm{T}_{d}\right)$ of $342^{\circ} \mathrm{C}$. The weight loss of this in this stage is about $35.8 \%$. The thermal behavior for GL and $\mathrm{GLAm}_{4}$ show a similar trend to the native leather with only a difference in that the main decomposition proceeds in two processes. The initial weight loss decreases up to $7.9 \%$ and $8.2 \%$ for GL and $\mathrm{GLAm}_{4}$ and this could be mainly related to the deposition of the poly-(GMA) and/or the reaction products of the poly-(GMA) with the DBA (reaction scheme 1) on the surface of the leather, which reduces its capacity to absorb moisture. The main decomposition process, on the other hand, for the two modified leather samples started at a relatively lower temperature than that of ungrafted leather. The differential thermogravemetric (DTG) curve of the GL shows two peaks with $\mathrm{T}_{d}$ of $317.2^{\circ} \mathrm{C}$ and $379.8^{\circ} \mathrm{C}$, and weight losses of $12.2 \%$ and $35.3 \%$, respectively. Meanwhile, the $\mathrm{GLAm}_{4}$ has the $\mathrm{T}_{d}$ two peaks at $272^{\circ} \mathrm{C}$ and $363^{\circ} \mathrm{C}$ with weight losses of $14.9 \%$ and $45.6 \%$, respectively. The observed lower main degradation temperature for $\mathrm{GL}$ and $\mathrm{GLAm}_{4}$ could be explained in terms of degradation effect caused by 
the action of $\mathrm{pH}$ medium, either for grafting bath for $\mathrm{GL}$ (as an acidic) or DBA chemical reagent for $\mathrm{GLAm}_{4}$ (as an alkaline).

\section{Scanning electron microscope}

The scanning electron microscope was used to study the morphology of some selected samples of unmodified leather, leather-g-polyGMA and grafted leather treated with DBA. From the micro-graphs (Figures 3 ), it is clear that the unmodified leather fibers are completely separated from each other, whereas, in case of grafted leather fibers aggregates of polyGMA can be noticed on the leather fibers which is a good evidence for the formation of polyGMA grafted on leather surface.

For the micrographs related to the grafted leather treated with DBA, it is observed that, the leather surface showed smooth fibers, soft grain and the fibers interfered with each other.

\section{Nitrogen content}

Table (1) shows the relation between the nitrogen contents and DBA concentration when the latter was reacted at different molar concentrations $(0.5-2 . .5)$ with leather-g-polyGMA. It is evident that the nitrogen content increases by increasing the DBA concentration from a ratio 0.5 up to 2.0 , after which, the nitrogen content decreases. Logically, the increment of amine concentration leads to more interactions via opening the epoxy functional group of GMA according to the following equation:

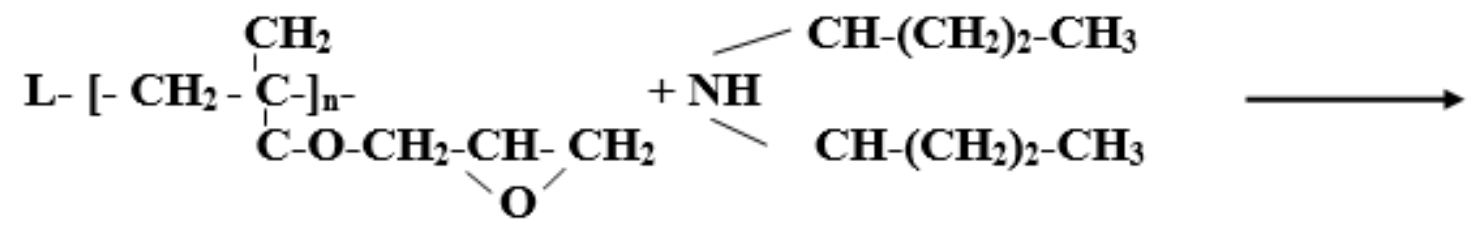

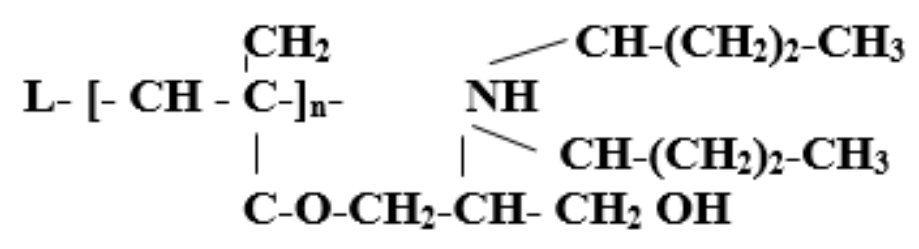

After DBA/epoxy concentration of 2.0 molar ratio, the nitrogen content was noticeably decreased due to the fact that, the highly amine concentration confer suitable basic medium which affect the solubility of amino acids existing in the collagen macromolecule.

\section{Mechanical properties:}

Table (1) shows the mechanical properties expressed as the tensile strength $(\mathrm{Kg})$ and elongation (\%) as well as the hardness (shore) of the modified and unmodified leather samples. As is evident, the tensile strength and the elongation (\%) increase after grafting with polyglycidyl methacrylate which could be related to the plasticizing effect of PGMA grafted in the matrix of the leather. Meanwhile, the tensile strength and elongation (\%) of the grafted and DBA treated leather samples decrease at amine/epoxy 
molar ratio of 0.5 and this could be ascribed to the opening up of the leather structure after the interaction between the epoxy group of the monomer and the amino group of the DBA. Increasing the amine/epoxy molar ratio value over 0.5 induces an increment in the tensile strength and elongation (\%) and reach a maximum at molar ratio value of 2.5. Logically, increasing the DBA bring about substantial improvement in the uniformity of the inter-fiber structure via more deposition of the reacted amine compound inside the fiber matrix. This finding's in accordance with that obtained by SEM study. The hardness values, on the other hand, of the grafted leather decrease by the addition of DBA and such decrease are directly proportional to the DBA concentration.

\section{Water absorption}

Table (1) shows the water absorption (\%) of $B L, G L$ and $G L$ treated with different DBA concentrations. It is evident that the water absorption firstly decreases after grafting with GMA. Treatment of grafted leather with different DBA concentrations is accompanied by an increase in the water absorption property till certain level after which it decreases. Increasing the water absorption by increasing the DBA concentration could be ascribed to the pronounced effect of the created tertiary amino group with its superior hydrophilic character in the molecular structure of leather. As the nitrogen content increases the magnitude of the butyl alkyl groups increases too causing creation of hydrophobic centers at the leather surface thereby preventing more water adsorption. This suggestion could be recognized via observing the variation in the leather morphological structure after DBA treatment.

\section{Dye property}

Seven sets of leather samples were independently dyed with acid and reactive dyes. Five sets of these samples are containing different DBA/epoxy content molar ratio of $0.5-2.5\left(\mathrm{GLAm}_{1}-\mathrm{GLAm}_{5}\right)$ and the other two sets are $G L$ and $B L$. The dyeing properties expressed as colour strength $(K / S)$ are shown in Table (1). For acid dye, it is evident that, the $G L$ acquires an improvement in the $K / S$ value than that of unmodified one. Moreover, introducing tertiary amino groups in the molecular structure of leather by reacting GL with DBA up to a certain DBA concentration brings about considerable increase in the dyeuptake, as evidenced by the values of K/S. The colour strength $(\mathrm{k} / \mathrm{s})$ values for the acid dyed leather samples follow the following descending order:

$\mathrm{GLAm}_{2}>\mathrm{GLAm}_{1}>\mathrm{GLAm}_{3}>\mathrm{GL}>\mathrm{GLAm}_{4}>\mathrm{BL}>\mathrm{GLAm}_{5}$

The noticeable increment of the colour strength $(\mathrm{k} / \mathrm{s})$ values for $\mathrm{GL}$ and $\mathrm{GLAm}_{1-4}$ than that for unmodified leather could be associated with the following aspects: a) opening up structure of the collagen fibrous through grafting and/or DBA treatment, b) direct interaction between the acid dye and the poly-GMA containing leather via ring opening of the epoxide groups, and c) increasing the magnitude of acid dye accumulation and penetration through $\mathrm{GLAm}_{1-4}$ due to formation of hydrogen bonding between the acid dye and additional basic tertiary amino functional groups [25]. 
The gradual increase of the dyeing behaviour from GLAm1 to GLAm2 could be ascribed to the relatively higher nitrogen content of GLAm2 (Table 1), which in turn brings about a significant increase in the dye hydrogen bond interaction. On the other hand, the observed decrease in the colour strength values for GLAm3 and GLAm4 could be interpreted in terms of blocking of the leather intermiclle size by dibutyl amine causing a limitation of dye penetration. Needless to say that the higher alkaline medium treatment using DBA/epoxy content ratio of 2.5 causes a significant decrement in the leather amine content which, in turn, affect the extent of dyeing due to the lack of hydrogen bond interaction.

For reactive dye, it is also evident (Table 1), that the $\mathrm{GLAm}_{1-5}$ have higher colour strength values as compared with the untreated leather L-g-poly GMA exhibits the lowest colour strength value. This is because the dyeing operation was carried out without addition of any buffering alkaline medium. Hence the colour strength will rely greatly on the basic character of the reacted DBA. Also, the dyeing of reactive dye occurs via chemical bond interaction between the substrate and the dye [26] Increasing the leather

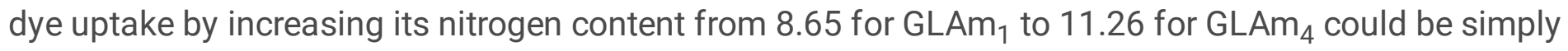
attributed to the basicity of leather substrate, which leads to increase in the extent of the nucleophile substitution reaction between the dye molecules and the modified leather substrate [27]. The significant drop in the colour strength value for GL can be attributed to the repulsion force between the anionic epoxy content of leather substrate and the anionic nature of reactive dye, causing less affinity for dye-GL interaction.

Table (1): Dependence of colour strength, water absorption and mechanical properties of leather grafted with GMA and treated with DBA on DBA concentration.

\begin{tabular}{|c|c|c|c|c|c|c|c|c|c|}
\hline \multirow{2}{*}{$\begin{array}{l}\text { Sample } \\
\text { Code }\end{array}$} & \multirow[t]{2}{*}{$\begin{array}{l}\text { Amine/epoxy } \\
\text { molar ratio }\end{array}$} & \multirow{2}{*}{$\begin{array}{l}\mathrm{N} \\
(\%)\end{array}$} & \multicolumn{2}{|c|}{$\begin{array}{l}\text { Color Strength } \\
(\mathrm{K} / \mathrm{S})\end{array}$} & \multicolumn{2}{|c|}{$\begin{array}{l}\text { Water } \\
\text { absorption } \\
\text { (\%) }\end{array}$} & \multicolumn{3}{|c|}{ Mechanical Properties } \\
\hline & & & $\begin{array}{l}\text { Acid } \\
\text { dye }\end{array}$ & $\begin{array}{l}\text { Reactive } \\
\text { dye }\end{array}$ & $\begin{array}{l}30 \\
\min \end{array}$ & $\begin{array}{l}120 \\
\min \end{array}$ & $\begin{array}{l}\mathrm{T} . \mathrm{S}^{*} \\
(\mathrm{Kg} / \mathrm{c})\end{array}$ & $\begin{array}{l}E^{\star *} \\
(\%)\end{array}$ & $\begin{array}{l}\text { Hardness } \\
\text { (shore) }\end{array}$ \\
\hline BL & - & 7.6 & 26.33 & 17.88 & 78.0 & 83.0 & 6.72 & 15 & 95 \\
\hline GL & - & 7.1 & 30.06 & 3.30 & 69.43 & 71.23 & 7.60 & 22 & 92 \\
\hline $\mathrm{GLAm}_{1}$ & 0.5 & 8.6 & 34.97 & 27.25 & 73.18 & 73.78 & 6.15 & 16 & 90 \\
\hline $\mathrm{GLAm}_{2}$ & 1.0 & 9.4 & 35.46 & 29.49 & 78.95 & 79.33 & 6.75 & 19 & 86 \\
\hline $\mathrm{GLAm}_{3}$ & 1.5 & 10.3 & 30.85 & 31.63 & 80.93 & 82.04 & 6.79 & 20 & 85 \\
\hline $\mathrm{GLAm}_{4}$ & 2.0 & 11.2 & 29.68 & 34.21 & 76.21 & 79.76 & 9.0 & 30 & 78 \\
\hline $\mathrm{GLAm}_{5}$ & 2.5 & 7.9 & 25.89 & 21.84 & 68.80 & 70.84 & 10.0 & 50 & 73 \\
\hline
\end{tabular}


$\mathrm{T} . \mathrm{S}^{\star}=$ Tensile strength; $\mathrm{E}^{\star \star}=$ Elongation

\section{Conclusions}

Grafting polymerization of GMA monomer onto natural leather was carried out via emulsion polymerization technique to obtain leather-g-GMA with grafting yield $26 \%$.

The obtained leather-g-GMA were treated by different ratios of dibutyl amine / epoxy ratios ranged from 0.5:2.5.

The obtained leather samples were characterized by FTIR, SEM and nitrogen content determination.

Mechanical properties, water absorption capacity and colour strength of acid and reactive dyes were also studied and the results indicated that leather samples with acid dye were found to increase by grafting or by increasing the amine/epoxy molar ratio up to a value of 1.0 after which it decreases.

\section{Declarations}

\section{Acknowledgment}

The authors extend their appreciation to the deanship of Scientific Research at University of Tabuk for funding this work through research group number RGP S-1441-0021.

\section{References}

1. Liao,J., Yang,L., Grashow,J., Sacks,M.S., "Molecular orientation of collagen in intact planar connective tissues under biaxial stretch" Acta Biomaterialia,1,pp:45:54,(2005).

2. Nashy,E.H., Osman,.O, Mahmoud,A.A., Ibrahim,M., "Molecular spectroscopic study for suggested mechanism of chrome tanned leather" ,Spectrochimica Acta Part A,88,pp:171:176,(2012).

3. Chen,K.W., Lin,L.C., Lee,W.C., "Analyzing the carbon footprint of the finished bovine leather: a case study of aniline leather" Energy Procedia, 61,pp:1063:1066, ( 2014 ).

4. Kanagara ,J., Chandra Babu, K., Mandal,A.B., "Recovery and reuse of chromium from chrome tanning waste water aiming towards zero discharge of pollution" Journal of Cleaner Production,16 ,pp:1807:1813,(2008) .

5. Saleem,R., Adnan,A., Qureshi,F.A., "Synthesis and application of formaldehyde free melamine glutaraldehyde amino resin as an effective retanning agent", Indian Journal of Chemical Technology, 22,pp: 48-55,(2015).

6. Yılmaz,O., Kantarli,C., Yuksel,M., Saglam,M., Yanik,J., "Conversion of leather wastes to useful products" Resources, Conservation and Recycling ,49,pp:436:448,(2007).

7. Li,Z., Paudecerf,D., Yang,J., "Mechanical Behaviour Of Natural Cow Leather In Tension" ACTA MECHANICA SOLIDA SINICA, 22,pp:37:44,(2009). 
8. Taghipour,M., Jalali,M., "Effect of clay minerals and nanoparticles on chromium fractionation in soil contaminated with leather factory waste" Journal of Hazardous Materials ,pp:127:133,(2015).

9. Sebestyén,Z., Jakab,E., Badea,E., Barta-Rajnai,E., Şendrea,C., Czégény,ZS., "Thermal degradation study of vegetable tannins and vegetable tanned leathers" Journal of Analytical and Applied Pyrolysis ,138,pp:178:187,(2019).

10. Sivakami,M.S., Gomathi,T., Venkatesan,J., JeongH,S., Kwon Kim,S., Sudha,P.N., "Preparation and characterization of nano chitosan for treatment wastewaters" International Journal of Biological Macromolecules ,57,pp204:212,(2013).

11. Cohen,N.S, Odlyha,M., Foster,G.M., "Measurement of shrinkage behaviour in leather and parchment by dynamic mechanical thermal analysis" Thermochimica Acta ,365,pp:111:117,(2000).

12. Seen Choi,S., Eun Ko, J., "Analysis of cyclic pyrolysis products formed from amino acid monomer" Journal of Chromatography $A$,1218, pp:8443:8455,(2011).

13. Teklay,A., Teklay ,G., Getachew,T., Yaynshet,T., Yaynshet,T.P., "Conversion of finished leather waste incorporated with plant fibers into value added consumer products - An effort to minimize solid waste in Ethiopia " Waste Management , 68, pp:45:55,(2017).

14. Hassan,R.A., "Analytical study of a manuscript, 'Tafsir Al khazin ' - the seventeenth century AD" ,Current Science International,4,pp:196:207,(2015).

15. Ibrahim,M.M., Mohamed,S.O., Hefni,Y.K., Ahmed,A.I., " Nanomaterials for Consolidation and Protection of Egyptian Faience form Matteria, Egypt” Journal of Nano Research ,56,pp:39:48,(2018).

16. ia, L., Ma, J., Gao, D., Lyu, B., Zhang, J., "Application of an amphoteric polymer for leather pickling to obtain a less total dissolved solids residual process" , Journal of Cleaner Production ,139,pp:788:795, (2016).

17. Liu,M., Ma,Z., Lyu,B., Gao,D., Zhang,J., “Enhancement of chromium uptake in tanning process of goat garment leather using nanocomposite" Journal of Cleaner Production ,133,pp:487:494,(2016).

18. Cao,S., Liu,B., Cheng,B., Lu,F., Wang,Y.,Li,Y., “Mechanisms of Zn(II) binded to collagen and its effect on the capacity of eco-friendly Zn-Cr combination tanning system", Journal of Hazardous Materials,321,pp:203:209,(2017).

19. Sundarapandiyana,S., Brutto,P.E., Siddhartha,G., Ramesh,R., Ramanaiah ,B., Saravanan,P., Manda,A.B., "Enhancement of chromium uptake in tanning using oxazolidine" Journal of Hazardous Materials, 190,pp:802:809,(2011).

20. Krishnamoorthy,G., Sadulla,S., Sehgal,P.K., Manda,A.B., " Greener approach to leather tanning process: D-Lysine aldehyde as novel tanning agent for chrome-free tanning" Journal of Cleaner Production ,42,pp:277:286,(2013).

21. Bicchieri,M., Valentini,F., Pascalicchio,F., Riccardi,M.L., Colaizzi,P., Del Re,C., Talamo,M., "The solution to an unresolved problem: Newly synthesized nanocollagen for the preservation of leather" Journal of Cultural Heritage,33,pp:1:9,(2018).

22. Strzelczyk, B., Bannach,L., Kurowska,A., " Biodeterioration of Archeological Leather" International Biodeterioration \& Biodegradation, 39 ,pp:301:309,(1997). 
23. Sun,X., Jin,Y., Lai,S., Pan,J., Du,W., Shi,L., “Desirable retanning system for aldehyde-tanned leather to reduce the formaldehyde content and improve the physical-mechanical properties" Journal of Cleaner Production,175 ,pp:199:206,(2018).

24. Agustí,E.Z., Galiana-Aleixandre,M.V., Bes-Pia,A., Mendoza-Roca,J.A., Risueno-Puchades,V., Segarra,V., "Pollution reduction in an eco-friendly chrome-free tanning and evaluation of the biodegradation by composting of the tanned leather wastes" Journal of Cleaner Production, 87,pp:874:881,(2015).

25. Bacardit,A., Burgh,S.V.D., Armengol,J., Ollé,L., "Evaluation of a new environment friendly tanning process" Journal of Cleaner Production, 65 ,PP:568:573,(2014).

26. Abdiyev,K.Z., Toktarbay,Z., Zhenissova,A.Z., Zhursumbaeva,M.B., Kainazarova,R.N., Nuraje,N., "The new effective flocculants - Copolymers of N,N-dimethyl-N,N-diallyl-ammonium chloride and N,Ndimethylacrylamide" Colloids and Surfaces A: Physicochem. Eng. Aspects 480 ,pp: 228:235,(2015).

27. Abd El-Monem,F., Hussain,A.I., NashyE..H.A., Abd El-Wahhab,H., Naser,A.M., "Nano-emulsion based on acrylic acid ester co-polymer derivatives as an efficient pre-tanning agent for buffalo hide” ,Arabian Journal of Chemistry , 10,pp:3861:3869,(2017).

\section{Figures}



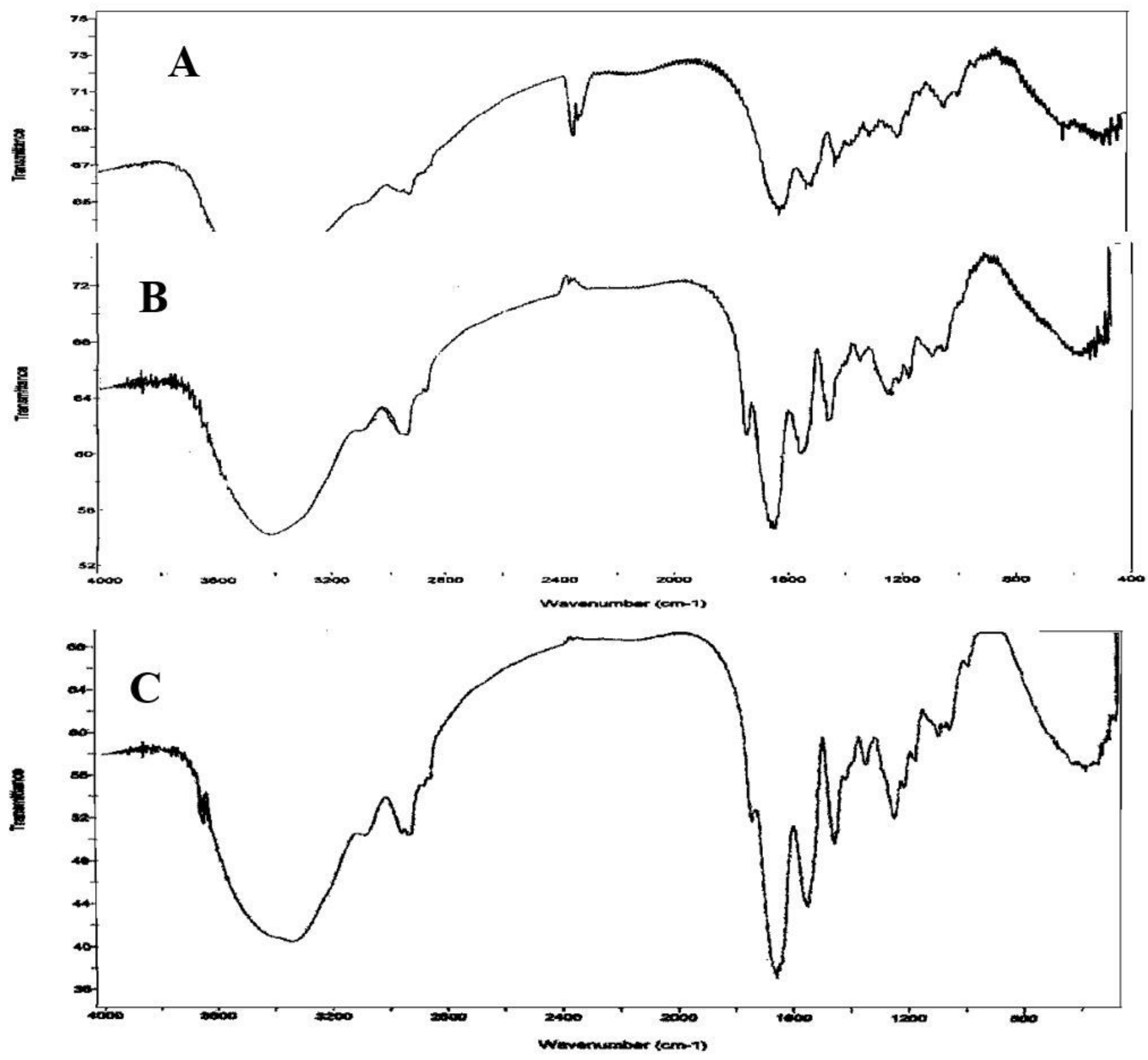

Figure 1

IR spectra for (A)ungrafted leather; (B)leather-g-polyGMA; and (C)grafted leather treated with dibutyl amine. 


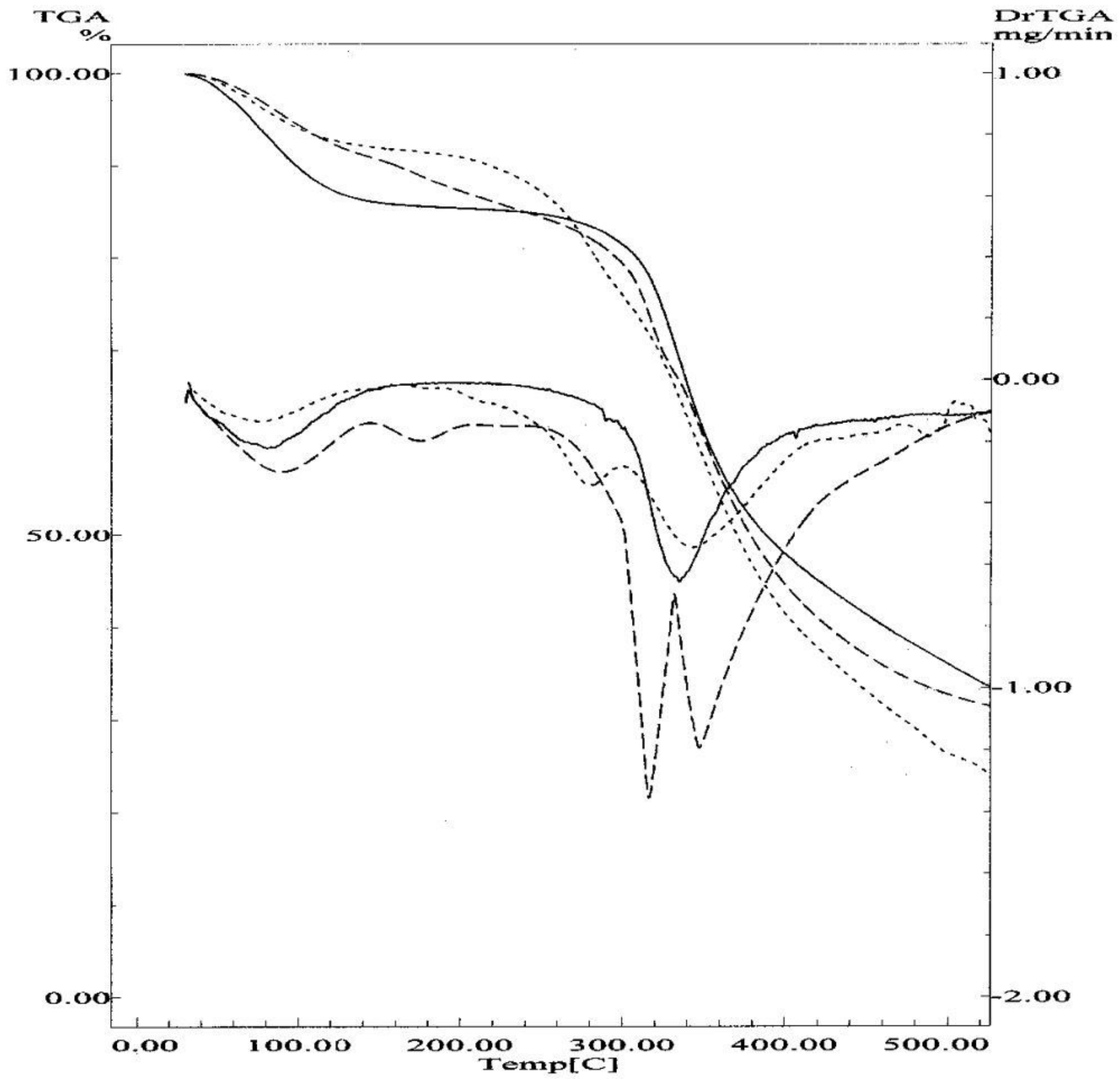

Figure 2

The TG/DTG curves for ungrafted leather ( - ); leather grafted with GMA (----); leather grafted with GMA and treated with DBA (--). 

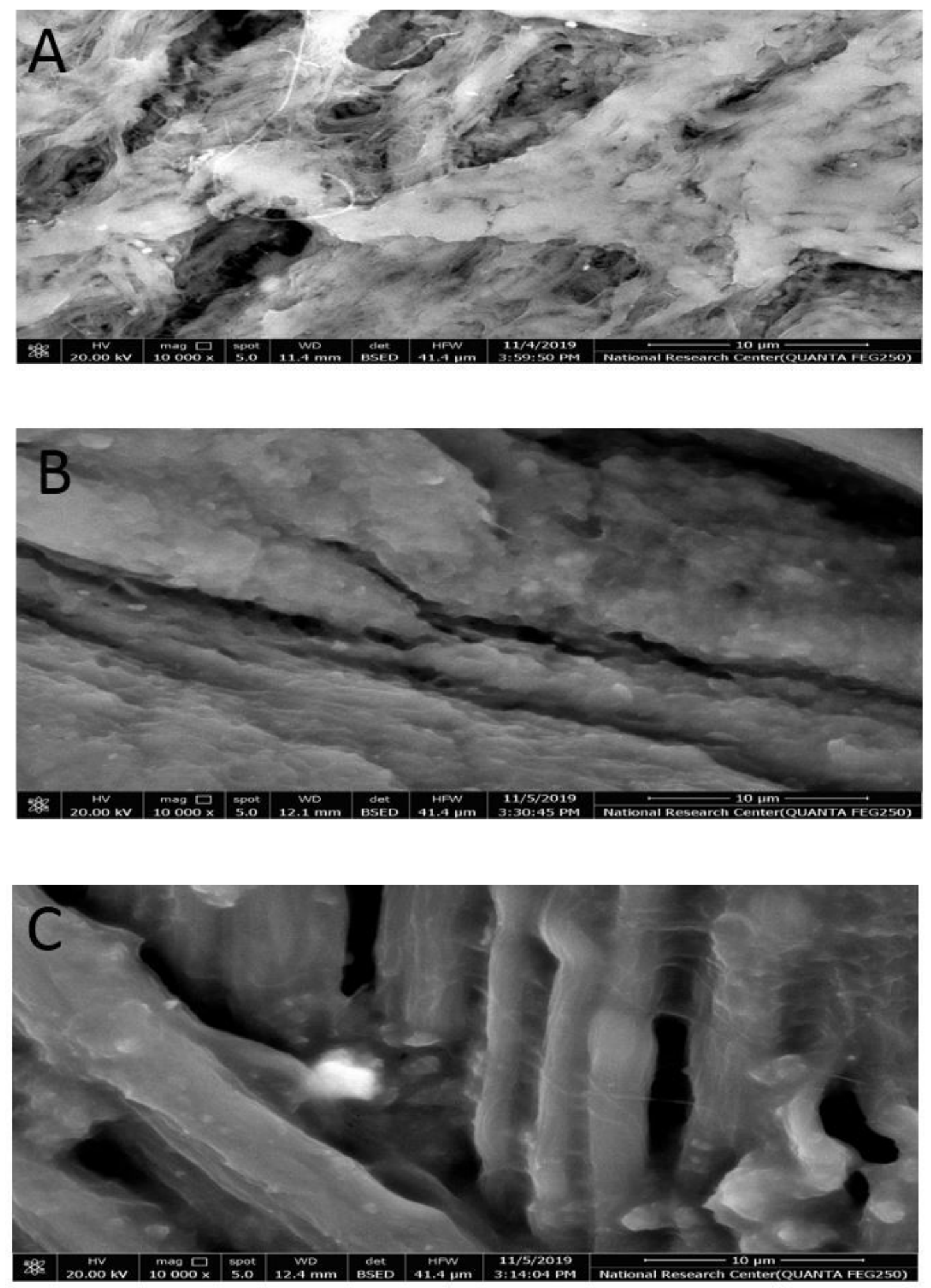

Figure 3

SEM for A) ungrafted leather, B) leather grafted with GMA, C) grafted leather treated with dibutyl . 